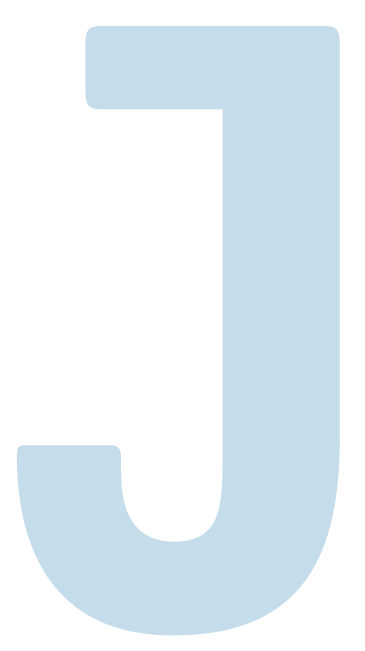

\title{
JUDICIALIZAÇÃO DA SAÚDE: ANÁLISE DE AÇÕES JUDICIAIS DEMANDADAS NA COMARCA DE SOBRAL, CEARÁ
}

HEALTH LITIGATION: ANALYSIS OF LAWSUITS FILED IN THE JUDICIAL DISTRICT OF SOBRAL,

CEARÁ

JUdiCIALIZACIÓN DE LA SALUd: ANÁLISIS DE ACCIONES JUDICIALES PRESENTADAS EN EL DISTRITO JUDICIAL DE SOBRAL, CEARÁ

Francisco José Leal de Vasconcelos ${ }^{1}$

Maria Socorro de Araújo Dias ${ }^{2}$

Maria José Galdino Saraiva ${ }^{3}$

Márcia Maria Santos da Silva 4

\section{RESUMO}

Este estudo teve por objetivo analisar os processos judiciais sobre saúde que tramitaram na Comarca de Sobral (CE) no período

Ede 2014 a 2016. Trata-se de pesquisa descritiva, orientada pela abordagem quantiqualitativa, tendo a base documental dos processos judiciais relacionados à saúde como fonte. Para registro dos dados, elaborou-se um formulário estruturado. Foram identificados 55 processos - 5 deles foram excluídos, por estar arquivados ou ter sido remetidos a recursos perante o Tribunal de Justiça (TJ), o que impossibilita a análise do processo físico. Dos 50 processos selecionados emergiram 3 categorias: a) Descrição do perfil sociodemográfico dos litigantes; b) Objeto e motivações das ações judiciais; e c) Evidências de judicialização da saúde em Sobral. Constatou-se aumento das demandas judiciais em defesa do direito à saúde nesse município no período de estudo.

Palavras-chave: Judicialização da Saúde; Direito à Saúde; Saúde Pública.

\footnotetext{
1. Enfermeiro. Bacharel em Direito. Especialista em Gestão do Sistema Único de Saúde (SUS) pela Universidade Estadual Vale do Acaraú (UVA). Aluno de mestrado em Saúde da Família na Rede Nordeste de Formação em Saúde da Família (Renasf). Sobral (CE), Brasil.

2. Enfermeira. Pós-Doutora em Cuidados Clínicos em Enfermagem e Saúde pela Universidade Estadual do Ceará (UECE). Professora do curso de graduação em Enfermagem na UVA. Diretora da Escola de Formação em Saúde da Família Visconde de Sabóia (EFSFVS). Sobral (CE), Brasil.

3. Pedagoga. Mestre em Ensino na Saúde pela UECE. Coordenadora pedagógica na EFSFVS. Sobral (CE), Brasil.

4. Assistente social. Mestre em Ensino na Saúde pela UECE. Coordenadora de ensino da EFSFVS. Sobral (CE), Brasil.
} 


\section{ABSTRACT}

This study aimed to analyze the health-related lawsuits filed in the Judicial District of Sobral, Ceará, Brazil, within the period from 2014 to 2016. This is a descriptive research, grounded in the quanti-qualitative approach, having the documentary database of health-related lawsuits as a source. For data recording, a structured form has been prepared. We have identified 55 lawsuits - 5 out of them were excluded, because they were cold cases or they have been sent to appeals before the Court of Justice (CJ), making it impossible to analyze the physical lawsuit. From the 50 lawsuits selected, 3 categories emerged: a) Description of the litigants' sociodemographic profile; b) Lawsuits' object and motivations; and c) Evidence of health litigation in Sobral. There was an increased number of lawsuits in defense of the right to health in this municipality during the study period.

Keywords: Health Litigation; Right to Health; Public Health.

\section{RESUMEN}

Este estudio tuvo como objetivo analizar los procesos judiciales acerca de salud que tramitaron en el Distrito Judicial de Sobral, Ceará, Brasil, en el período de 2014 a 2016. Se trata de una investigación descriptiva, orientada bajo el enfoque cuanticualitativo, que tiene la base de datos documental de los procesos judiciales relacionados con la salud como fuente. Para registro de datos, se ha preparado un formulario estructurado. Hemos identificado 55 procesos - 5 de ellos fueron excluidos, porque fueron casos archivados o han sido remitidos a recursos ante el Tribunal de Justicia (TJ), por lo que es imposible analizar el proceso físico. De los 50 procesos seleccionados, surgieron 3 categorías: a) Descripción del perfil sociodemográfico de los litigantes; b) objeto y motivaciones de las demandas judiciales; y c) Evidencias de judicialización de la salud en Sobral. Hubo un mayor número de demandas judiciales en defensa del derecho a la salud en este municipio durante el periodo de estudio.

Palabras clave: Judicialización de la Salud; Derecho a la Salud; Salud Pública.

\section{INTRODUÇÃO}

Nos últimos anos, o Estado brasileiro tem vivenciado maior protagonismo do Poder Judiciário, fenômeno também voltado à garantia do direito fundamental à saúde, e com ele surgiram desafios para todas as esferas de poder, fato que demanda profunda e criteriosa análise de juristas e doutrinadores do Direito, por afetar a operacionalização administrativa, orçamentária e financeira das políticas de saúde pública.

A busca de tratamentos medicamentosos estimulou a atuação de outras partes interessadas com vistas à afirmação de seus direitos e possibilitou maior vinculação entre os campos do Direito e da Saúde, traduzida pelo grande volume de processos judiciais, todos amparados pela Constituição Federal de 1988 (CF/1988) - que determinou o amplo direito da população à saúde, assim como delegou ao Estado o dever de promovê-la e custeá-la.

Segundo informações disponíveis no sistema de acompanhamento de processos do Conselho Nacional de Saúde (CNJ) - órgão de controle da atuação administrativa e financeira do Poder Judiciário -, em junho de 2014 tramitavam 330.630 ações judiciais relacionadas à saúde em todos os Tribunais de Justiça (TJ) estaduais e 62.291 ações judiciais sobre saúde em todos os Tribunais Regionais Federais (TRF) ${ }^{1,2}$. Em comparação aos anos anteriores, 0
CNJ registra que até 2011 tramitavam 221.423 e 19.557 ações judiciais sobre saúde nos TJ e TRF, respectivamente números que revelam significativo aumento de litigantes em busca da garantia do direito à saúde ${ }^{1,2}$.

Quanto às ações sobre saúde demandadas nos TJ dos 9 estados da região Nordeste do Brasil, houve pequeno aumento, se observados os relatórios mencionados: 10.130 ações judiciais até 2011 e 17.026 ações judiciais até 2014 . Esses relatórios apontam, ainda, que no TJ do Ceará não houve alteração do número de ações judiciais sobre saúde: cerca de 8.350 processos. Entretanto, ainda assim, essa quantidade coloca o Ceará em $4^{\circ}$ lugar nacional e em $1^{\circ}$ lugar no Nordeste em termos de demandas judiciais sobre saúde.

Em relação à estrutura judiciária, Sobral (CE) possui 1 fórum vinculado ao TJ do Ceará, com 3 varas cíveis, 3 varas criminais, 1 juizado especial - a Vara Única de Família e Sucessões. Também existem no município a subseção da Justiça Federal no Ceará, onde funcionam a $18^{a}, 19^{\text {a }}$ e $31^{a}$ varas federais, a $1^{\text {a }}$ e a $2^{\text {a }}$ varas da Justiça do Trabalho e a $24^{\mathrm{a}}$ e $121^{\mathrm{a}}$ zonas eleitorais.

Diante do exposto, este estudo se funda na necessidade de ampliar o debate sobre a judicialização da saúde na circunscrição do município em análise, visto que inexistem estudos específicos sobre a matéria nesse território; além disso, no cenário nacional e macrorregional, percebe-se um aumento exponencial do volume de litígios sobre essa 
temática, a exemplo do Ceará (aumento $88 \%$ dos processos judiciais), o que implica custos para o sistema de saúde; considerando o território nacional, identificou-se que as decisões judiciais têm elevado os custos das cirurgias e congestionado as Unidades de Terapia Intensiva (UTI) ${ }^{3,4}$. A judicialização da saúde corrobora a importância de conhecer o cenário envolvido para buscar soluções eficazes e conciliadoras.

0 fenômeno da judicialização ilustra a saúde como dimensão complexa: trata-se de um conceito difuso, por não resultar apenas de fatores biológicos e genéticos, também envolve fatores socioambientais, econômicos e culturais, além do estilo de vida das pessoas ${ }^{4}$.

A definição da Organização Mundial da Saúde (OMS) realça essa complexidade ao considerar saúde um completo bem-estar físico, mental e social; portanto, não se limita à ausência de doença ou enfermidade. A CF/1988 buscou inspiração nesse conceito, ao determinar em seu artigo 196 que:

A saúde é direito de todos e dever do Estado, garantido mediante políticas sociais e econômicas que visem à redução do risco de doença e de outros agravos e ao acesso universal e igualitário às ações e serviços para sua promoção, proteção e recuperação ${ }^{5}$.

Um estudo sobre o diálogo institucional como recurso para lidar com a judicialização da saúde indica que:

A promulgação da Constituição de 1988 promoveu uma enorme transformação na sociedade e nas instituições brasileiras, criando um ambiente livre e democrático onde $o[p]$ ovo passou a conhecer os seus direitos, além do Estado ter recebido a incumbência constitucional de promover o bemestar das pessoas através da realização dos direitos fundamentais elencados no artigo $6^{\circ}$, por exemplo, a saúde, a educação, a moradia etc. ${ }^{6: 178}$.

A saúde foi
alçada à
categoria
de direito
fundamental

Assim, a legislação brasileira dispõe que todas as pessoas contem, em território nacional, com a cobertura de um sistema de saúde público, universal e gratuito. - cujo imperativo é a ação do Estado para garanti-lo a todos os cidadãos ${ }^{7}$.

Desse modo, o direito à saúde "ainda se constitui como cláusula pétrea, uma vez que, em virtude de sua associação direta com o direito à vida", deve ser protegido. Qualquer ameaça a esse direito deve ser submetida à apreciação jurisdicional pelo prejudicado, resguardados os limites do possivel, da proporcionalidade e da razoabilidade, no âmbito da CF/19887.

Entretanto, as ações judiciais relacionadas à saúde têm atacado, expressiva e crescentemente, os serviços públicos e privados e têm gerado certo desconforto na gestão de recursos financeiros e orçamentários, visto que altera diretamente o planejamento elaborado pelos gestores e profissionais da saúde.

Essa constatação foi motivada pela atuação do Poder Judiciário, o qual, durante muitos anos, esteve fortemente orientado pelo convencimento unicamente pessoal dos magistrados. Ou seja, não se via padronização e/ou limites nas decisões dos juízes, assim como tais decisões não aprofundavam questões mais específicas do universo da saúde - apesar das inúmeras iniciativas do CNJ para criar mecanismos e estratégias de orientação aos juízes.

Um estudo sobre a judicialização da saúde brasileira mostrou preocupação com a crescente quantidade de ações judiciais, a cada ano, sem que sejam apresentadas propostas para reverter esse fenômeno ou reavaliar/reformular as políticas públicas assistenciais no setor saúde ${ }^{8}$.

Apresenta-se, assim, o objetivo principal deste estudo: Analisar os processos judiciais sobre saúde que tramitaram na Comarca de Sobral, no período de 2014 a 2016, que tenham esse município e/ou o Estado do Ceará no polo passivo.

\section{METODOLOGIA}

Trata-se de pesquisa de natureza descritiva, orientada pela abordagem quantiqualitativa, subsidiada em base documental dos processos judiciais relacionados ao setor saúde. Para fins de registro dos dados, elaborou-se um formulário estruturado, com questões relativas ao perfil sociodemográfico do demandante, pedido que deu causa ao processo, valor da causa e motivação para buscar a via judicial.

Esse formulário foi utilizado na coleta de informações essenciais dos processos judiciais que, entre 2014 e 2016, tramitavam na $1^{a}$ e na $3^{a}$ varas cíveis - que recebem demandas relacionadas à saúde -, vinculadas ao TJ do Ceará e localizadas na Comarca de Sobral. 
Na $1^{\text {a }}$ Vara Cível, no período indicado, foram identificados 23 processos no Sistema Processual (SPROC), todos com jurisdição no município de Sobral, e relacionados à palavrachave saúde - tendo Sobral e/ou o estado do Ceará no polo passivo.

$\mathrm{Na} 3^{\mathrm{a}}$ Vara Cível, os processos que versam sobre saúde são identificados com tarjeta vermelha na capa do processo; essa medida conferiu maior agilidade à localização dos 32 processos de interesse para esta pesquisa.

Dos 55 processos identificados, 5 foram excluídos por estar arquivados ou ter sido remetidos a recursos perante o TJ, fato que impossibilita a análise do processo físico. Dessa forma, nossa amostra foi constituída por 50 processos, analisados individualmente com vistas a extrair as informações indicadas no instrumento de coleta de dados; em seguida, foram avaliados os aspectos relacionados à judicialização da saúde em Sobral.

\section{RESULTADOS}

\section{Descrição do perfil sociodemográfico dos litigantes}

Este artigo apresenta, de forma pioneira, uma análise da judicialização da saúde em Sobral com base em processos físicos. A judicialização da saúde instalou-se em Sobral e esse fenômeno acompanhou o crescimento quantitativo que

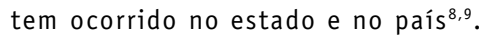

Aqui, uma questão inicial é que o sistema eletrônico utilizado pelo Poder Judiciário cearense apresenta limitações quanto ao filtro de informações necessárias para operacionalizar a análise dos processos. Aparentemente, a configuração desse sistema eletrônico prioriza o registro e o monitoramento dos atos processuais, fato que dificulta outros tipos de consulta. Outro estudo também indica essa dificuldade ${ }^{8}$, ao caracterizar a judicialização do direito à saúde no Ceará por meio dos processos registrados nos sistemas de informação do Poder Judiciário de 1998 a 2012.

Em relação aos 50 processos avaliados neste estudo, a Tabela 1 ilustra que $58 \%$ dos litigantes são do sexo feminino e $42 \%$ do sexo masculino; a grande maioria reside na zona urbana $(76 \%)$ e há predominância de idades entre 19 e 60 $\operatorname{anos}(64 \%)$.

Tabela 1 - Perfil dos litigantes em ações judiciais que tramitavam na Comarca de Sobral de 2014 a 2016.

\begin{tabular}{|c|c|c|}
\hline Variáveis & $N^{L}$ & $\%$ \\
\hline \multicolumn{3}{|l|}{ Sexo } \\
\hline Feminino & 21 & 58 \\
\hline Masculino & 29 & 42 \\
\hline
\end{tabular}

\begin{tabular}{lcc}
\hline \multicolumn{1}{c}{ Variáveis } & $\mathrm{N}^{\mathrm{L}}$ & $\%$ \\
\hline \hline Idades & 3 & \\
1 a 7 anos & 0 & 6 \\
7 a 12 anos & 1 & 0 \\
13 a 18 anos & 32 & 2 \\
19 a 60 anos & 14 & 64 \\
$>60$ anos & & 28 \\
Residência & 38 & \\
Zona Urbana & 12 & 76 \\
Zona Rural & & 24 \\
\hline
\end{tabular}

Nota: $\mathrm{N}^{\mathrm{L}}=$ número de litigantes.

Fonte: Elaborada pelos autores.

A maior parte dos litigantes é composta de adultos jovens e idosos, fato que evidencia um processo de adoecimento da população de maior idade e, consequentemente, a busca por soluções terapêuticas e medicamentosas junto ao Poder Judiciário, visando a restabelecer a saúde. Esse achado tem relação direta com a transição demográfica pela qual passa o país.

A população brasileira reduziu suas taxas de fecundidade e natalidade e encontra-se em processo de envelhecimento; com isso, surgem muitas enfermidades na população adulta, o que provoca aumento da quantidade de demandas junto ao sistema de saúde e a seguridade social ${ }^{10}$. Percebe-se que tais mudanças na estrutura populacional exigem respostas oportunas do Estado, boa parte delas ofertada pelo Poder Judiciário - tendo em vista a limitação operacional e/ou legal das demais esferas de poder.

Corroborando os resultados desta pesquisa, estudo realizado em Minas Gerais sobre o acesso a medicamentos por meio do Poder Judiciário também evidenciou predominância do sexo feminino nos processos judiciais e idade superior a 19 anos. Isso sugere que a população feminina adulta acessa os serviços de saúde com maior frequência, consequentemente, a partir de diagnósticos médicos e indicações terapêuticas, busca a tutela do Estado para garantir seu direito à saúde ${ }^{11}$.

A predominância de litigantes residentes na zona urbana de Sobral (76\%) tem relação com a expansão urbana ocasionada pela crescente migração rural-urbana - influenciada pela formação de uma sociedade urbano-industrial ${ }^{12}$.

Nesse sentido, chama atenção o fato de que 2 dos processos analisados envolvem moradores de municípios distintos do foco da análise; entretanto, a Defensoria Pública do Estado do Ceará patrocinou suas defesas e a Comarca de Sobral as recebeu, apesar de encontrar-se fora da circunscrição judiciária de competência da $1^{a}$ e $3^{a}$ varas civeis.

Em outras palavras, 0 aumento da quantidade de residentes em Sobral - incluídas aquelas pessoas que vêm dos municípios circunvizinhos, em busca de melhor qualidade de

SANARE, Sobral - V.16 n.02,p.06-13, Jul./Dez. - 2017 - 9 
vida, trabalho, educação etc. - deu-se em meio às mudanças demográficas e à transição epidemiológica (doenças crônicas não transmissíveis), associadas à ampliação das desigualdades sociais e econômicas - situação que reflete diretamente o processo de adoecimento das pessoas e aumenta a demanda por serviços prestados pelo Estado. Portanto, era de esperar que mais habitantes da zona urbana buscassem seus direitos pela via judicial em comparação aos habitantes da zona rural: $88 \%$ da população do município vivem na zona urbana, de acordo com dados do censo de 2010, do Instituto Brasileiro de Geografia e Estatística (IBGE) ${ }^{13}$.

\section{Objeto e motivações das ações judiciais}

Dentre os 50 casos avaliados, $70 \%$ apresentaram laudo médico nos autos do processo, indicando a urgência da demanda. A inclusão de documento médico explicitando o quadro de gravidade do paciente não é uma exigência legal no processo, porém, considerando que os magistrados não têm formação em Saúde, mostra-se de suma importância toda e qualquer informação que colabore com a formação do convencimento do julgador. Além disso, trata-se de alternativa que permite respaldar as decisões do Poder Judiciário em casos de medida liminar ou se houver questionamento da falta de equidade entre os usuários que buscam o Sistema Único de Saúde (SUS) e aqueles que pedem a tutela do Estado-juiz para garantir seu direito.

Já em relação aos motivos que justificaram o litigante a buscar o amparo do Estado-juiz para garantir seu direito, este estudo constatou relativo equilíbrio entre os procedimentos cirúrgicos e os medicamentos disponíveis e não disponíveis na relação do SUS, achado que destoa da literatura.

As demandas relacionadas a medicamentos se destacam como as mais requeridas pelos litigantes no Ceará ${ }^{9}$. No Distrito Federal, o bem mais requerido na judicialização da saúde é o acesso UTI na rede privada. Isso sugere que o contexto epidemiológico e demográfico, as estratégias de gestão do sistema de saúde e o comportamento das pessoas de cada território influenciam diretamente a quantidade e a natureza das demandas judiciais ${ }^{14}$.

Tabela 2 - Motivos que justificaram a busca pela tutela do Estado-juiz nas ações judiciais que tramitavam na Comarca de Sobral de 2014 a 2016

\begin{tabular}{lcc}
\hline Justificativa & N $^{\mathrm{A}}$ & $\%$ \\
\hline $\begin{array}{l}\text { Medicamento existente na Rename/ } \\
\text { Remume }\end{array}$ & 9 & 18 \\
$\begin{array}{l}\text { Medicamento não existente na } \\
\text { Rename/Remume }\end{array}$ & 8 & 16 \\
$\begin{array}{l}\text { Cirurgia de média complexidade } \\
\text { custeada pelo SUS }\end{array}$ & 1 & 2 \\
$\begin{array}{l}\text { Cirurgia de média complexidade não } \\
\text { custeada pelo SUS }\end{array}$ & 3 & 6 \\
\hline
\end{tabular}

\begin{tabular}{lcc}
\hline Justificativa & N $^{\mathrm{A}}$ & $\%$ \\
\hline \hline $\begin{array}{l}\text { Cirurgia de alta complexidade } \\
\text { custeada pelo SUS }\end{array}$ & 10 & 20 \\
$\begin{array}{l}\text { Cirurgia de alta complexidade não } \\
\text { custeada pelo SUS }\end{array}$ & 10 & 20 \\
$\begin{array}{l}\text { Insumo } \\
\text { Internamento compulsório }\end{array}$ & 3 & 6 \\
$\begin{array}{l}\text { Órtese/prótese } \\
\text { Reforma de ambiência e locação de } \\
\text { equipamentos }\end{array}$ & 1 & 2 \\
Complemento Nutricional & 1 & 4 \\
\hline
\end{tabular}

Nota: Rename = Relação Nacional de Medicamentos Essenciais; Remume = Relação Municipal de Medicamentos Essenciais; $N^{A}$ = número absoluto de ações judiciais demandadas.

Fonte: Elaborada pelos autores.

\section{Evidências de judicialização da saúde em Sobral}

Ao analisar as 50 ações judiciais sobre saúde, constatouse que 8 delas foram demandadas em 2014, 24 em 2015 e 18 em 2016, configurando, portanto, a curva crescente da judicialização do direito à saúde em Sobral. Um estudo confirma esse achado por meio de revisão integrativa de artigos extraídos da base do Centro Latino-Americano e do Caribe de Informação em Ciências da Saúde (Bireme) - houve crescimento do número de ações judiciais ${ }^{8}$.

No que concerne ao valor da causa, observou-se que a maioria das ações judiciais se encontra entre $R \$ 10.001,00$ e $\mathrm{R} \$ 50.000,00(38 \%)$. Se as ações judiciais com valor entre R\$ $1.001,00$ e $R \$ 10.000,00$ fossem somadas a elas, a quantidade de ações alcançaria $72 \%$ do total. A existência desse valor na petição inicial atende a determinação legal do Código de Processo Civil (CPC), além disso, o valor exprime, o quantum significativo daquele litígio, ou seja, é a valoração simbólica do bem jurídico a ser protegido ${ }^{15}$.

Tabela 3 - Valor da causa nas ações judiciais que tramitavam na Comarca de Sobral de 2014 a 2016.

\begin{tabular}{lcc}
\hline Valor da Causa & NA $^{\mathrm{A}}$ & $\%$ \\
\hline Até $R \$ 1.000,00$ & 7 & 14 \\
De $R \$ 1.001,00$ a $\mathrm{R} \$ 10.000,00$ & 17 & 34 \\
De $R \$ 10.001,00$ a $\mathrm{R} \$ 50.000,00$ & 19 & 38 \\
De $R \$ 50.001,00$ a $\mathrm{R} \$ 100.000,00$ & 4 & 8 \\
$>\mathrm{R} \$ 100.000,00$ & 3 & 6 \\
\hline
\end{tabular}

Nota: $\mathrm{N}^{\mathrm{A}}=$ número absoluto de ações judiciais demandadas. Fonte: Elaborada pelos autores.

0 valor da causa, aqui detalhado, reflete 0 valor do bem requerido judicialmente, o qual não está padronizado/ tabelado no âmbito do setor privado. Na prática, o valor do bem relativo à saúde, anotado em orçamento nos autos 
de cada processo, é determinado pelo médico sem qualquer parâmetro - no caso de cirurgias de média e alta complexidade - e pela iniciativa privada, a partir dos parâmetros de lucratividade - no caso dos medicamentos, dos insumos, das órteses/próteses e demais bens. Registre-se que, no curso do processo, em nenhum momento se questiona se o valor do bem orçado pelo profissional liberal e/ou pela pessoa jurídica e apontado em documento nos autos respeita a tabela SUS ou equivale aos padrões do mercado.

Vale lembrar que, dentre os 3 processos com valor da causa $>\mathrm{R} \$ 100.000,00,1$ processo pede que o Estado do Ceará e o Município de Sobral assumam o custeio de um procedimento cirúrgico de transplante de traqueia sintética, realizada no exterior, a valor de $R \$ 350.000,00$. 0 fato curioso é que esse tratamento não possui evidências científicas que comprovem sua eficácia. Nesse caso o magistrado não concedeu a tutela antecipada.

0 estudo aponta, ainda, que $72 \%$ dos processos analisados possuem laudos emitidos por médicos vinculados à administração pública e aos estabelecimentos conveniados com o SUS; $24 \%$ foram elaborados por profissionais de estabelecimentos exclusivamente privados e $4 \%$ das ações não têm laudo médico, embora haja estudos com predomínio de prescrições do setor privado ${ }^{11}$.

Ainda acerca da quantidade de laudos emitidos por médicos do serviço público, outro estudo apontou dados semelhantes, mas relatou grande quantidade de médicos indicando procedimentos e medicamentos não constantes nos protocolos padrão do SUS ${ }^{9}$.

No caso dos prescritores de Sobral, a Secretaria Municipal da Saúde realiza alinhamento permanente com a categoria médica, para uso dos protocolos e das relações oficiais de procedimentos e medicamentos, contudo, considerando a crise financeira vivenciada pelos estados e municípios ${ }^{16,17}$, assim como os longos e complexos trâmites burocráticos da administração pública, constatou-se que, no período analisado, houve redução da quantidade de alguns procedimentos ofertados pelo SUS e a exclusão de outros; ademais, ocorreu desabastecimento de alguns medicamentos e insumos, influenciado pela falta de matéria-prima para fabricação de inúmeros medicamentos e por limitações de ordem financeira.

Esses fatos indicam que o Poder Executivo ficou temporariamente impossibilitado de ofertar os produtos/ serviços a muitos usuários, situação que se soma ao fato de existirem muitos bens pleiteados nas demandas judiciais que não compunham e não compõem as relações oficiais.

A análise dos processos na Comarca de Sobral aponta que, em $72 \%$ deles, o magistrado concedeu liminarmente ao litigante o acesso ao bem relativo à saúde requerido na petição inicial. Número mais elevado foi encontrado em

\section{...há tendência de crescimento do número de demandas judiciais em defesa do direito à saúde...}

outro estudo, que evidencia $91,4 \%$ dos processos sobre saúde deferidos liminarmente pela Justiça do Estado do Ceará9.

Considerem-se, ainda, fatos relevantes ocorridos na tramitação desses processos: em uma das liminares concedidas ao requerente em desfavor do Município de Sobral não houve cumprimento da determinação por parte do gestor da saúde, fato que motivou o Ministério Público do Ceará a denunciar este último por crime de desobediência, além de formalizar pedido de reparação de danos morais à parte prejudicada - às expensas da pessoa física do representante da Secretaria da Saúde. Outro processo indicou que um parecer do Núcleo de Evidências foi decisivo para o indeferimento de um pedido de liminar - por se tratar de medicamento sem evidência científica.

Por último, considerando a revisão de literatura e as informações coletadas nesses processos judiciais, mostrase inquietante o silêncio do Município de Sobral com o recebimento de tantas liminares. No universo pesquisado, identificou-se apenas uma contestação, o que sugere que o ente municipal concorda com os pleitos dos litigantes.

\section{CONCLUSÃO}

Esta pesquisa evidenciou que há tendência de crescimento do número de demandas judiciais em defesa do direito à saúde em Sobral nos últimos anos, motivada pela ampliação do acesso aos serviços públicos de saúde. Tanto que se observou grande volume de demandas por parte dos profissionais do SUS.

0 equilíbrio entre a quantidade de bens e serviços pleiteados pelos litigantes, discutidos como motivos que deram causa ao processo, revela a tentativa e o esforço da gestão municipal para ofertar uma estrutura mínima de serviços, distribuídos uniformemente em todo o território.

Ainda assim, mostra-se necessário fortalecer as instituições e os órgãos que compõem o SUS no território desse município visto que muitas das demandas judicializadas são procedimentos, medicamentos e insumos inclusos nas relações oficiais e que, por um motivo ou outro, houve descontinuidade na entrega de produto/serviço ofertado pelo poder público, motivando a busca pela via judicial.

0 fortalecimento da Defensoria Pública do Estado do 
Ceará na Comarca de Sobral também reflete o aumento da judicialização da saúde, revelado pela grande quantidade de litigantes que reside na zona urbana desse município - onde os direitos são demandados pela via judicial.

Também vale registrar a importância de aperfeiçoar os sistemas eletrônicos de acompanhamento de processos no Poder Judiciário, tendo em vista que a configuração adotada permite uma busca limitada de dados aos operadores do Direito e aos pesquisadores em geral.

Para concluir, reflete-se que a judicialização da saúde está exposta aos interesses econômicos de indústrias, empresas privadas e profissionais liberais, assim como se constata que esse fenômeno constitui importante instrumento para garantir o direito à saúde. Contudo, mostra-se necessário que os gestores da saúde e os operadores do Direito dialoguem constantemente antes de buscar a via judicial. Durante o trâmite processual, deve-se garantir a universalidade e a integralidade da assistência à saúde sem prejudicar as finanças públicas.

\section{CONTRIBUIÇÃO DOS AUTORES}

Francisco José Leal de Vasconcelos contribuiu com o delineamento e a realização da pesquisa e a redação do manuscrito. Maria Socorro de Araújo Dias contribuiu com a realização da pesquisa e a redação e revisão crítica do manuscrito. Maria José Galdino Saraiva contribuiu com a redação e revisão crítica do manuscrito. Márcia Maria Santos da Silva contribuiu com a redação e revisão crítica do manuscrito.

\section{REFERÊNCIAS}

1. Brasil. Relatório de cumprimento da Resolução CNJ n. 107 [document on the internet]. Brasília (DF): Conselho Nacional de Justiça; 2014 [cited 2016 0ct 22]. Available from: http://www.cnj.jus.br/images/programas/forumdasaude/ demandasnostribunais.forumSaude.pdf

2. Brasil. Relatório de cumprimento da Resolução CNJ n. 107 [document on the internet]. Brasília (DF): Conselho Nacional de Justiça; 2011 [cited 2016 0ct 22]. Available from: http:// www.cnj.jus.br/images/programas/forumdasaude/relatorio atualizado da resoluca0107.pdf

3. Custos da saúde com processo na Justiça aumentam $88 \%$ no CE [document on the internet]. 2016 Jun 4 [cited 2016 Jun 5]. Available from: http://diariodonordeste.verdesmares. com.br/cadernos/cidade/custos-da-saude-com-processo-najustica-aumentam-88-no-ce-1.1561138

4. Santos L. Direito à saúde e qualidade de vida: um mundo de corresponsabilidades e fazeres In: Santos $L$, organizer. Direito da saúde no Brasil. Campinas (SP): Saberes; 2010. p. $x-y$.
5. Brasil. Constituição 1988. Constituição da República Federativa do Brasil. Brasília (DF): Senado; 1988.

6. Aguiar Júnior CAM, Vasconcelos FJL, Brayner JCM, Barros FEE. 0 diálogo institucional como possibilidade de enfrentamento da judicialização da saúde. In: Dias MSA, organizer. Saúde, direito e educação: encontro de saberes. Sobral (CE): Ed. UVA; 2016. p. x-y.

7. Asensi FD. Judicialização da saúde e Conselho Nacional de Justiça: perspectivas e desafios. In: Nobre MAB, Silva RAD, coordinators. $0 \mathrm{CNJ}$ e os desafios da efetivação do direito à saúde. 2. ed. Belo Horizonte: Fórum; 2013. p. x-y.

8. Dias MSA, Gomes DF, Dias TA, Silva LCC, Brito MCC, Carneiro Neto MC. Judicialização da saúde pública brasileira. Revista Brasileira de Políticas Públicas [serial on the internet]. 2016 [cited 2017 Dec 5];6(2):132-45. Available from: file:///D:/4012-19241-1-PB.pdf

9. Nunes CFO, Ramos Júnior AN. Judicialização do direito à saúde na região Nordeste, Brasil: dimensões e desafios. Cad Saúde Colet [serial on the internet]. 2016 [cited 2017 Feb 4];24(2):192-199. Available from: http://www.scielo.br/ $\mathrm{pdf} / \mathrm{cadsc} / \mathrm{v} 24 \mathrm{n} 2 / 1414-462 \mathrm{X}$-cadsc-24-2-192.pdf

10. Miranda GMD, Mendes ACG, Silva ALA. Desafios das políticas públicas no cenário de transição demográfica e mudanças sociais no Brasil. Interface Comun Saúde Educ [serial on the internet]. 2016 [cited 2017 Feb 4];21(61):30920. Available from: http://www.scielo.br/scielo.php?pid=S1 $41432832016005025103 \&$ script $=$ sci_abstract\&tlng=pt

11. Machado MAA, Acurcio FA, Brandão CMR, Faleiros DR, Guerra Jr AA, Cherchiglia ML, et al. Judicialização do acesso a medicamentos no estado de Minas Gerais, Brasil. Rev Saúde Pública [serial on the internet]. 2011 [cited 2017 Feb 4];45(3):590-8. Available from: http://www.scielo.br/scielo. php?script $=$ sci arttext \&pid $=$ S0034-89102011000300018

12. Marques C, Frey $H$. As mudanças habitacionais em regiões metropolitanas brasileiras. Revista Brasileira de Gestão Urbana [serial on the internet]. 2015 [cited 2017 Feb 4];7(2):250-67. Available from: http://www.scielo.br/pdf/ urbe/v7n2/2175-3369-urbe-7-2-250.pdf

13. Brasil. Censo Demográfico 2010: características gerais da população, religião e pessoa com deficiência [document on the internet]. Rio de Janeiro: IBGE; 2010 [cited 2017 Feb 4]. Available from: https://biblioteca.ibge.gov.br/visualizacao/ periodicos/94/cd_2010_religiao_deficiencia.pdf

14. Diniz D, Machado TRC, Panalva J. A judicialização da saúde no Distrito Federal, Brasil. Ciênc Saúde Coletiva [serial on the internet]. 2014 [cited 2017 Feb 4];19(2):591-8. Available from: http://www.scielo.br/scielo.php?pid=S1413$81232014000200591 \&$ script $=$ sci_abstract\&tlng $=p t$

15. Marinoni LG, Arenhart SC. Curso de processo civil. Processo de conhecimento. 10. ed. São Paulo: Revista dos Tribunais; 2011 . v. 2. 
16. Moreira R. Heitor lamenta corte de $10 \%$ nas verbas da saúde [document on the internet]. 2017 [cited 2017 Dec 5]. Available from: http://blogs.diariodonordeste.com.br/ robertomoreira/saude/heitor-lamenta-corte-de-10-nasverbas-da-saude/

17. Ribeiro G. Medicamentos de alto custo viram uma questão de Justiça no Ceará [document on the internet]. 2014 [cited 2017 Feb 2]. Available from: http://diariodonordeste. verdesmares.com.br/cadernos/cidade/medicamentos-dealto-custo-viram-uma-questao-de-justica-no-ceara-1.842103

Recebido em 05/10/2017 Aprovado em 19/10/2017

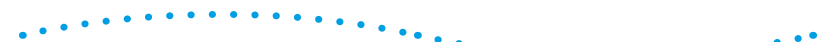

$\ldots \ldots \ldots \ldots \ldots \ldots \ldots \ldots \ldots \ldots$

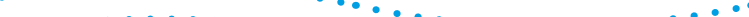

$\ldots \ldots \ldots \ldots \ldots \ldots \ldots$
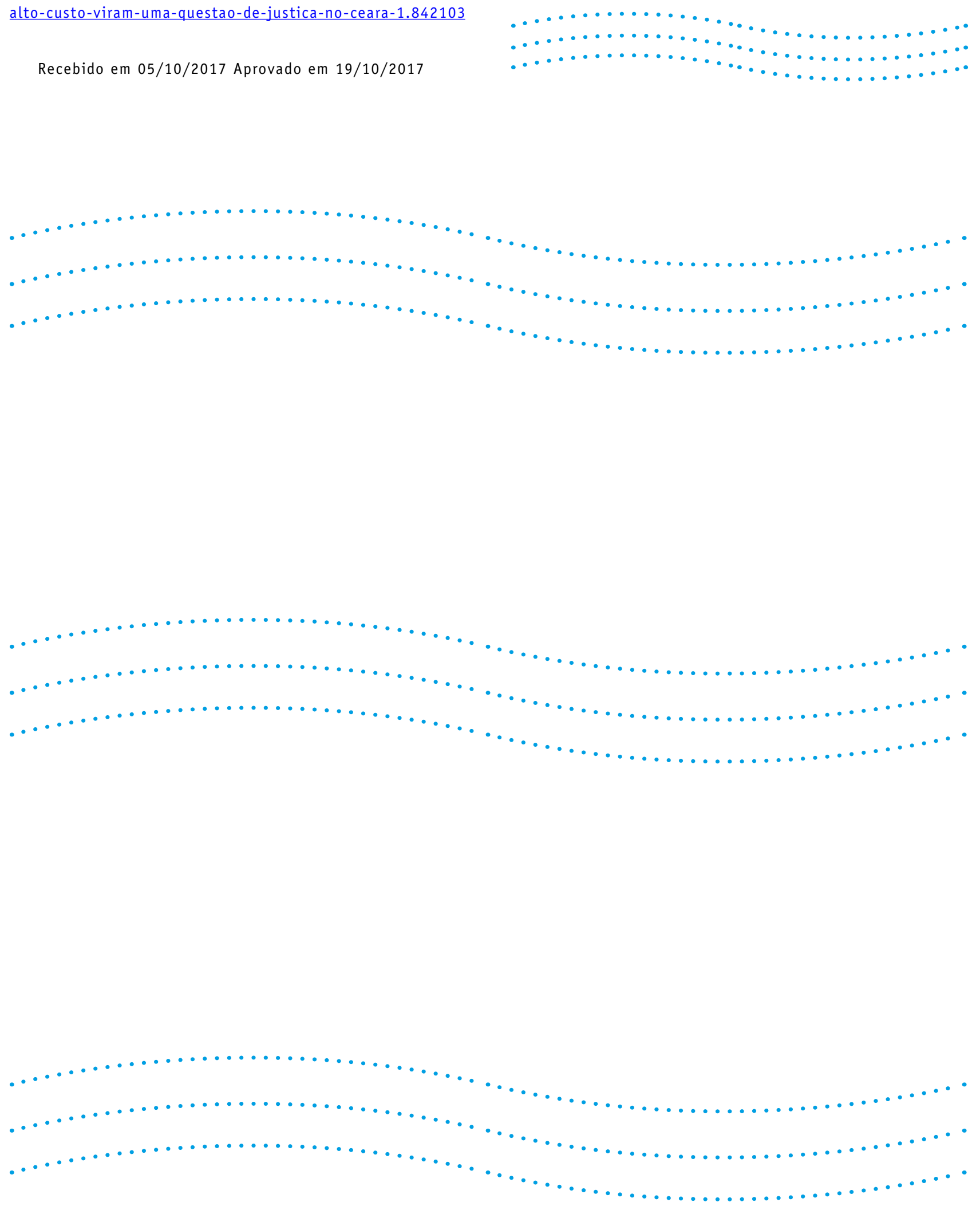